\title{
Non-elite marathon runners: health, training and injuries
}

\author{
P. Hølmich, MD, S.W. Christensen, MD, E. Darre, MD, F. Jahnsen, MD and T. Hartvig, MD \\ Wonderful Copenhagen Marathon Study Group
}

\begin{abstract}
A questionnaire was given to all participants of the Wonderful Copenhagen Marathon 1986 regarding demographic information, health, training, previous injuries and methods used to prevent these. A total load of 2158 Danish runners participated and 1426 (68 per cent) replied. Fifty per cent of the runners were training $30-60 \mathrm{~km}$ per week and 25 per cent more than $60 \mathrm{~km}$ per week. Forty-one per cent were members of running clubs. The runners were equally distributed between all social groups.

Most runners were slim (mean BMI 22.3 \pm 1.87 (SD)), healthy, non-smokers who rarely suffered from serious injuries, but 31 per cent had had injuries that prevented them from training during the last year. Nearly all performed stretching exercises and methods to avoid injuries. Fifty per cent of the runners tried to optimize their performance by changing their diet in the days before the run. Seventeen per cent used the classical high carbohydrate diet and 33 per cent other special diets.
\end{abstract}

Keywords: Marathon runners, health, training, injuries, demographics

\section{Introduction}

The increasing number of marathon entries shows that a large group of non-elite marathon runners has developed. To take part in a marathon and, even more importantly, to finish a marathon is a demanding physical task, and many experience unpleasant side effects at the end of a marathon.

The aim of the present study was to describe the typical non-elite marathon runner. What is his training condition, social status, running experience, method of training and what does he do to avoid injuries?

\section{Material and methods}

The Wonderful Copenhagen Marathon is an open entry marathon. The 1986 race took place on 17 May. There were 2158 Danish runners of whom 1808 (84 per cent) completed the course in times ranging from $2: 15 \mathrm{~h}$ to more than 5:00 h. All runners received a questionnaire regarding demographic information, health, training, previous injuries and the methods used to avoid injuries. There were 1426 (68 per cent) replies of which 1310 were from males and 116 from females. For statistical calculation the Mann-Withney test was used with a five per cent level of significance.

Address for correspondence: Dr Per Hølmich, Gersonsvej 12, DK2900 Hellerup, Denmark

(C) 1989 Butterworth \& Co (Publishers) Ltd 0306-3674/89/030177-02 \$03.00

\section{Results}

The average age of the male respondents was 34 years (range 11 to 77 years). Eighty four per cent had been running for more than two years, and 37 per cent for more than six years. A total of 850 (65 per cent) had run a marathon before in an average time of between 3:20 and 3:30 h (range 2:30 to over 4:00 h). A large number of the respondents 503 (41 per cent) were members of running or athletic clubs.

Table 1 shows the distribution of the respondents by social group. Group 1 is the economically highest ranking, and correspondingly group 5 is the lowest ${ }^{1}$.

The average height of the male responders was 179 $\mathrm{cm}(151-203 \mathrm{~cm})$ and the average weight was $73.3 \mathrm{~kg}$ (37-100 kg). We expressed body fat using the Body Mass Index (BMI), also known as the Quetelet index. A BMI over 25 indicates obesity; below 20 underweight $^{2}$. The BMI of the male respondents can be seen in Table 2.

Two of the runners suffered from chronic disease; one from arterial hypertension and one from bronchial asthma. Fourteen per cent were regular smokers and 39 had suffered from minor disease during the last month before the race. Half the runners trained 30-60 $\mathrm{km} /$ week and 25 per cent more than $60 \mathrm{~km} /$ week. Only seven per cent were training more than $90 \mathrm{~km} /$ week (Table 3). Twenty six had completed a marathon in the past five weeks before this competition.

The number of injuries preventing the runners from training or working is shown in Table 4, in relation to the weekly training distance. Almost all runners (1203 $\approx 92$ per cent) performed stretching exercises regularly; 77 per cent warmed up and 54 per cent

Table 1. Social groups among the male participants

\begin{tabular}{lccr}
\hline & & number & $\%$ \\
\hline Social group & 1 & 169 & 12.9 \\
& 2 & 193 & 14.7 \\
& 3 & 124 & 9.5 \\
& 4 & 256 & 19.5 \\
& 5 & 244 & 18.6 \\
\hline Unknown & & 324 & 24.8 \\
\hline
\end{tabular}

Table 2. Body mass index of male participants

\begin{tabular}{lrr}
\hline BMI & number & $\%$ \\
\hline$<20$ & 93 & 7 \\
$20-25$ & 960 & 73 \\
$>25$ & 99 & 8 \\
\hline Unknown & 158 & 12 \\
\hline
\end{tabular}


Table 3. Weekly training distance among the male participants

\begin{tabular}{lr}
\hline$k m /$ week & number \\
\hline $0-30$ & 180 \\
$31-60$ & 672 \\
$61-90$ & 242 \\
$91-120$ & 75 \\
$121-$ & 15 \\
Unknown & 126 \\
\hline Total & 1310
\end{tabular}

Table 4. Number of injuries preventing runners from training or attending work according to the weekly training distance. Male participants

\begin{tabular}{lcrrrr}
\hline \multirow{2}{*}{$\mathrm{km} /$ week } & number & \multicolumn{3}{c}{ Prevented from } & \multicolumn{3}{c}{ Prevented from } \\
& training & $\%$ & work & $\%$ \\
\hline $0-30$ & 180 & 53 & 22.9 & 0 & 0 \\
$30-60$ & 672 & 177 & 24.7 & 11 & 1.5 \\
$60-90$ & 242 & 75 & 30.7 & 6 & 2.6 \\
$90-120$ & 75 & 25 & 33.3 & 1 & 1.3 \\
$120-$ & 15 & 8 & 53.3 & 0 & 0 \\
Unknown & 126 & & & & \\
\hline Total & 1310 & 410 & 31.3 & 18 & 1.3 \\
\hline
\end{tabular}

Table 5. Methods aimed at injury prevention among male participants

\begin{tabular}{|c|c|}
\hline$N=1310$ & number \\
\hline Warming up & 1007 \\
\hline Warming down & 707 \\
\hline Stretching & 1203 \\
\hline Special protection of the feet & 277 \\
\hline the nipples & 379 \\
\hline the axilla/groin & 395 \\
\hline
\end{tabular}

warmed down in connection with training or races (Table 5). Protection of the skin with Vaseline, plaster etc. was used by nearly one third of the runners (Table 5). Of the male runners, 226 (17 per cent) used the classical high carbohydrate diet and 427 (33 per cent) some other special diet in the days before competition.

\section{Discussion}

Our study confirms that the average age for marathon runners is the beginning of the third decade in $^{3-6}$ in contrast to runners training for shorter distances ${ }^{5}$. The social status of the responders is evenly distributed on all social groups in contrast to the findings of Jacobs and Berson ${ }^{4}$ who, in a study of 10000 metre runners, found a high proportion (84 per cent) of runners with at least a college education and 54 per cent having a yearly income of $\$ 30000$ or more in 1984 .

Campbell' showed that the BMI is a significant predictor of running speed in long-distance running. It is therefore not surprising that elite marathon runners are very thin individuals ${ }^{6,8}$. In this study most nonelite marathon runners were also slim as seven per cent had a BMI below 20, and 73 per cent had a BMI within the normal range, only eight per cent having a BMI over 25.

Marathon runners, even on the non-elite level, are characteristically thorough in their preparations.
Thirty seven per cent of the responders had been training for more than six years. Our weekly mileage is consistent with other non-elite studies. In a previous study of elite runners we found that two-thirds were running 90 to $150 \mathrm{~km} /$ week $^{8}$. Other studies have found the injury incidence to be associated with the weekly mileage ${ }^{4,5}$

The risk of serious injuries does not seem to be high when training for a marathon. Only 1.3 per cent of the respondents had injuries preventing them from attending work. In contradiction, Linde found an incidence of ten per cent of injuries of this severity in a group of orienteers. Minor injuries preventing the runner from training were sustained in 31 per cent of the runners during the year prior to this 1986 marathon. This is lower than reported in previous studies of long-distance runners ${ }^{3-5}$.

An explanation might be increasing seriousness among the marathon runners regarding nutrition, shoes and injury prevention. We found that 92 per cent performed stretching exercises and 77 per cent warmed up (Table 5).

Dietary manipulation to optimize performance was used by 50 per cent of the runners. Seventeen per cent used the classical high carbohydrate diet involving three days of low carbohydrate diet and two sessions of intense exercise followed by three days of high carbohydrate diet without exercise ${ }^{10}$. Thirty three per cent used other forms of special diet, mainly a high carbohydrate diet, in the days before the race without a carbohydrate depletion period ${ }^{11}$. We have not been able to find other studies concerning dietary manipulation among non-elite long-distance runners.

\section{References}

1 Hansen, E.J. Social class classification in Denmark. National Institute of Social Investigations, publication 82, Copenhagen, 1978

2 Garrow, J.S. 'Treat obesity seriously' Churchill Livingstone, London, 1981

3 Maughan, R.J. and Miller J.D.B. Incidence of trainingrelated injuries among marathon runners Brit J Sports Med 1983, 6, 162-165

4 Jacobs, S.J. and Berson, B.L. Injuries to runners: A study of entrants to a 10,000 meter race Am J Sports Med 1986, 14, 151-155

5 Lysholm, J. and Wiklander, J. Injuries in runners $A m$ J Sports Med 1987, 15, 168-171

6 Costill D.L. Physiology of marathon running JAMA 1972, 9, 1024-1029

7 Campbell, M.J. Predicting running speed from a simple questionnaire Brit J Sports Med 1985, 3, 142-144

8 Hölmich, P., Darre, E., Jahnsen F. and Hartvig-Jensen, T. The elite marathon runner: Problems during and after competition Brit J Sports Med 1988, 1, 19-21

9 Linde, F. Sick-leave among elite runners on account of sports injuries Ugeskr Laeger 1984, 15, 1166-1168

10 Ahlborg, B., Bergström, J., Brohult, J., Ekelund, L-G., Hultman, E. and Maschio, G. Human muscle glycogen content and capacity for prolonged muscle exercise after different diets Forsvarsmedicin 1976, 3, 85-99

11 Sherman, W.M. and Costill, D.L. The marathon: Dietary manipulation to optimize performance $A m J$ Sports Med 1985, 12, 44-51 